\title{
HISTÓRICO DE FORMAÇÃO E CONSOLIDAÇÃO DA PESQUISA COLABORATIVA EM REDE: OIIIIPe A LaPEADE EM FOCO
}

\author{
HISTORIA DE FORMACIÓN Y CONSOLIDACIÓN DE LA \\ INVESTIGACIÓN COLABORATIVA EN RED: OIIIIPe y LaPEADE EN FOCO
}

\author{
MAPPING OUT THE CREATION AND CONSOLIDATION OF A \\ COLLABORATIVE NETWORK RESEARCH: A FOCUS ON OIIIIPe AND \\ LaPEADE
}

\author{
Mônica Pereira dos Santos ${ }^{1}$ \\ Mylene Cristina Santiago ${ }^{2}$ \\ Leyse Monick França Nascimento ${ }^{3}$
}

RESUMO: O Laboratório de Pesquisa, Estudos e Apoio à Participação e à Diversidade em Educação (LaPEADE /FE/UFRJ) vem desenvolvendo pesquisas que versam sobre as temáticas de inclusão em educação, a fim de apoiar e promover a participação e a diversidade em educação nas dimensões culturais, políticas e práticas das instituições e sistemas institucionais. No que diz respeito ao Observatório Internacional de Inclusão, Interculturalidade e Inovação Pedagógica (OIIIIPe), trata-se de uma pesquisa colaborativa em rede que se consolidou em 2016, mas que vem sendo desenvolvida, desde 2004, pelo LaPEADE, em parceria com instituições de ensino estrangeiras. Objetivamos com este artigo apresentar um rastreamento histórico acerca da parceria do LaPEADE com o OIIIIPe no que tange aos processos de inclusão e exclusão, no âmbito do ensino superior, e de forma exploratória expor resultados parciais de um questionário realizado com dois gestores da UFRJ no que se refere às concepções de inclusão, interculturalidade e inovação pedagógica em contextos do ensino superior. No tocante à metodologia, nosso estudo tratase de uma pesquisa colaborativa, bibliográfica, documental e com uso da etnografia digital (POLIVANOV, 2015) Como resultado, destacamos os desafios do trabalho em rede e a consolidação do observatório, tendo como parâmetro as atuais políticas públicas de internacionalização da ciência e tecnologia brasileiras; o fortalecimento de redes de pesquisa e parcerias interinstitucionais; o intercâmbio de discentes e docentes; assim como a realização de eventos acadêmicos em quatro Estados brasileiros.

${ }^{1}$ Universidade Federal do Rio de Janeiro (UFRJ), Rio de Janeiro - RJ- Brasil. Professora Associada da Faculdade de Educação da UFRJ. ORCID: <https://orcid.org/0000-0002-7057-7804>. E-mail: monicapes@gmail.com

${ }^{2}$ Universidade Federal de Juiz de Fora (UFJF), Juiz de Fora - MG - Brasil. Professora adjunta do Departamento de Educação. Universidade Federal Fluminense (UFF), Campus Gragoatá, Niterói, RJ, Brasil, Professora do Programa de Pós-Graduação em Educação. ORCID: <https://orcid.org/0000-0002-03546215>. E-mail: mylenesantiago87@gmail.com

${ }^{3}$ Universidade Federal do Rio de Janeiro (UFRJ), Rio de Janeiro - RJ - Brasil. Doutoranda do Programa de Pós-Graduação em Educação (PPGE). ORCID: 〈https://orcid.org/0000-0002-0354-6215>. E-mail: leysemonick79@gmail.com 
PALAVRAS-CHAVE: Inclusão em educação. Interculturalidade. Inovação pedagógica. Formação de professores. Educação Superior.

RESUMEN: El Laboratorio de Investigación, Estudios y Apoyo a la Participación y la Diversidad en Educación (LaPEADE /FE/UFRJ) viene desarrollando investigaciones que versan sobre las temáticas de inclusión en educación, a fin de apoyar y promover la participación y la diversidad en educación en las dimensiones culturales, políticas y prácticas de las instituciones y sistemas institucionales. En lo que se refiere al Observatorio Internacional de Inclusión, Interculturalidad e Innovación Pedagógica (OIIIIPe), se trata de una investigación colaborativa en red que se consolidó en 2016, pero que viene siendo desarrollada desde 2004 por LaPEADE en asociación con instituciones de enseñanza extranjera. En este artículo presentaremos un rastreo histórico acerca de la asociación de LaPEADE con el OIIIIPe en lo que se refiere a los procesos de inclusión y exclusión, en el ámbito de la enseñanza superior y de forma exploratoria, presentar resultados parciales de un cuestionario realizado con dos gestores de la UFRJ en lo que se refiere a las concepciones de inclusión, interculturalidad e innovación pedagógica en contextos de la enseñanza superior. En lo que se refiere a la metodología, nuestro estudio se trata de una investigación colaborativa, bibliográfica, documental y con uso de la etnografía digital (POLIVANOV, 2015). Como resultado destacamos los desafíos del trabajo en red y la consolidación del observatorio, teniendo como parámetro las actuales políticas públicas de internacionalización de la ciencia y tecnología brasileñas; el fortalecimiento de redes de investigación y asociaciones interinstitucionales; el intercambio de discentes y docentes, así como la realización de eventos académicos en cuatro estados brasileños.

PALABRAS CLAVE: Inclusión en educación. Interculturalidad. Innovación pedagógica. Formación de profesores. Educación superior.

ABSTRACT: The Laboratory of Research, Studies and Support to Participation and Diversity in Education of the Faculty of Education of the Federal University of Rio de Janeiro (LaPEADE/FE/UFRJ) has, for a long time, carried out research about the different themes of inclusion in education. The International Observatory of Inclusion, Interculturality and Pedagogic Innovation (OIIIIPe) is a collaborative research network initiated in 2004 and consolidated in 2016 under LaPEADE's coordination. In this paper we aim to present a historical mapping out about the partnerships established between LAPEADE and OIIIIPe with regards to the processes of inclusion and exclusion in Higher Education. We also aim to present some preliminary results, at an exploratory level of analysis, of a questionnaire carried out with two managers of the Federal University of Rio de Janeiro concerning their conceptions of inclusion, interculturality and pedagogic innovation in the higher education context. Our method is of multiple characteristic, encompassing collaborative, bibliographical, documentary and digitally ethnographical researches. The results point to the challenges of working in a network and the consolidation of the Observatory under the lights of the current Brazilian internationalization policies. Despite the challenges, we were able to identify the strengthening of research network and institutional partnerships; an enhancement in the students and teachers' academic mobility and in the organization and execution of academic events in four Brazilian states. 
KEYWORDS: Inclusion in Education. Interculturality. Pedagogic Innovation. Teacher Education. Higher education

\section{Introdução}

O Observatório Internacional de Inclusão, Interculturalidade e Inovação Pedagógica (OIIIIPe) é uma rede de pesquisadores que envolve 23 universidades nacionais e internacionais com o propósito de investigar contradições e perspectivas emergentes em propostas e experiências de inclusão, interculturalidade e inovação pedagógica desenvolvidas no processo de formação de educadores em universidades nacionais e internacionais, por meio de variadas metodologias e de subprojetos de pesquisa que serão desenvolvidos colaborativamente pelas universidades participantes, sendo respeitadas as demandas regionais de cada Instituição de Ensino Superior (IES).

Desde 2015, a equipe do Rio de Janeiro, propositora e coordenadora do projeto, tem buscado criar estratégias que garantam a organização do trabalho colaborativo em rede. Nossa primeira intervenção foi a produção do projeto de pesquisa de forma colaborativa, ou seja, cada pesquisador incluía objetivos específicos ao projeto "guarda-chuva", de modo que ações e proposições locais convergissem com o objetivo geral do projeto, respeitando as diferentes metodologias e filiações teóricas adotadas pelos pesquisadores e suas respectivas instituições.

Esse exercício tem sido muito profícuo no sentido de combater o isolamento do docente nas Instituições de Ensino Superior e tem promovido debates importantes no sentido de viabilizar troca de experiências e diferentes debates teórico-metodológicos envolvendo os conceitos-chave da pesquisa: inclusão, interculturalidade e inovação pedagógica.

Para que estejamos em constante diálogo, temos realizado reuniões virtuais mensais com as equipes, por meio do Adobe Connect, um aplicativo que viabiliza a participação de todos e a visualização dos materiais em discussão. Para além dos encontros virtuais, temos dois encontros semestrais presenciais, que nos possibilitam avançar nas pesquisas e dar o tom colaborativo da proposta no sentido de apresentar os trabalhos que temos desenvolvido em nossas instituições, voltados para o OIIIIPe.

\section{Inclusão, interculturalidade e inovação pedagógica: definições preliminares}


O primeiro passo dado na elaboração de um questionário a ser aplicado em todas as universidades participantes foi definir os conceitos de inclusão, interculturalidade e inovação pedagógica de modo a contemplar os pesquisadores ou talvez assumir consensos teórico-metodológicos provisórios, visto que adotamos a perspectiva de certezas e saberes sempre em construção e, portanto, temporários.

Vale dizer que as pesquisadoras da equipe coordenadora têm trabalhado com uma perspectiva que denominam de Omnilética (SANTOS; SANTIAGO, 2009a, 2009b; 2013; SANTOS, 2013), a qual pode ser aplicada à análise de qualquer fenômeno social, político, cultural. Dado que nossa trajetória acadêmica partiu de (mas não se limitou a) compreender os fenômenos de in/exclusão em Educação, adotamos tal perspectiva para definir inclusão, o que foi aceito pelos outros pesquisadores. Para a compreensão de interculturalidade e inovação pedagógica, também poderíamos adotar a perspectiva Omnilética. No entanto, deixamos a cargo dos participantes optarem ou não pela sua utilização, tendo em vista que muitos já trabalhavam com outros métodos. Assim, essas duas categorias foram definidas de forma mais genérica, a fim de dialogarem tanto com a perspectiva Omnilética quanto com outras.

Para efeitos do presente artigo, discutiremos as três categorias (inclusão, interculturalidade e inovação pedagógica) a partir do olhar omnilético, motivo pelo qual ele será detalhado a seguir.

A perspectiva Omnilética começou a ser elaborada no ano de 2009, durante reuniões de estudo do LaPEADE, e foi apresentada pela primeira vez em anais de congressos por Santos e Santiago (2009a, 2009b). Na época, esse nome representou (e continua representando) um importante momento de um longo processo de estudos e pesquisas coordenados por Santos, Santiago e Melo ${ }^{4}$ desde a fundação do Lapeade, em 2003. Esse momento, por assim dizer, foi marcado, simultaneamente, por movimentos aparentemente opostos. Ao mesmo tempo que adotamos categorias como a tridimensionalidade (culturas, políticas e práticas) de Booth e Ainscow (2011), a complexidade de Morin $(2005,2015)$ e a dialética materialista de Lukács $(2003,2010)$ categorias estas que, a nosso ver, são centrais para a compreensão dos fenômenos humanos

${ }^{4}$ Professoras Mônica Pereira dos Santos (UFRJ), Sandra Cordeiro de Melo (UFRJ) e Mylene Cristina Santiago (UFF), coordenadoras do LaPEADE. A Professora Mônica fundou o LaPEADE em 2003 e o coordena desde então. As Professoras Sandra e Mylene associaram-se ao Laboratório como coordenadoras em 2010. 
e sociais e para a constituição da perspectiva Omnilética -, abandonamos certas facetas sobre a forma como nossos autores as utilizam.

No que tange à tridimensionalidade, Booth e Ainscow (2011) colocam a dimensão de culturas como a base do desenvolvimento de políticas e práticas de inclusão. Para os autores:

Esta dimensão está ligada à criação de comunidades seguras, acolhedoras, estimulantes e receptivas, nas quais todos são valorizados. Valores compartilhados de inclusão são desenvolvidos e repassados a todos os funcionários, crianças e suas famílias, gestores, comunidades do entorno e a todos aqueles que que trabalham na e com a escola. Os valores das culturas inclusivas orientam decisões sobre políticas e práticas de momento a momento de forma que o desenvolvimento [da escola] é coerente e contínuo. A incorporação das mudanças dentro das culturas da escola assegura que elas sejam integradas nas identidades dos adultos e crianças e passadas adiante aos recém-chegados à escola (BOOTH; AINSCOW, 2016, p. 50).

Na perspectiva Omnilética, culturas têm o mesmo significado como o proposto por Booth e Ainscow (2016), com a diferença de que elas se equiparam em importância às dimensões de políticas e práticas. Ainda sobre a tridimensionalidade, Booth e Ainscow (2016) tratam a dimensão das políticas como arranjos administrativos que garantem o suporte necessário às práticas de inclusão. Eles nos dizem o seguinte sobre políticas:

Esta dimensão assegura que a inclusão permeie todos os planos para a escola e envolva a todos. Políticas encorajam a participação de todas as crianças e funcionários a partir do momento em que se associam à escola. Elas encorajam a escola a alcançar todas as crianças da localidade e a minimizarem pressões excludentes. Políticas de apoio envolvem todas as atividades que aumentem a capacidade de uma instituição de responder à diversidade de seus membros de forma a valorizar a todos igualmente. Todas as formas de apoio são interligadas em uma estrutura única que garante a participação de todos e o desenvolvimento da escola como um todo (BOOTH; AINSCOW, 2016, p. 50).

Em nossa perspectiva, políticas dizem respeito, para além desse aspecto dos arranjos, às intenções explicitadas (em palavras orais ou escritas, ou por outras maneiras, e não necessariamente de forma constantemente clara) que se fundam em culturas práticas, assim como também fundam novas culturas e práticas.

Com referência à dimensão das práticas, Booth e Ainscow (2016) as definem como uma dimensão cujo peso curricular adquire predominância, definindo-as como estando ligadas: 
[...] ao desenvolvimento do que é ensinado e do que é aprendido, e como as coisas são ensinadas e aprendidas de forma a refletirem valores e políticas inclusivas. As implicações dos valores de inclusão para a estruturação dos conteúdos das atividades de aprendizagem estão trabalhadas [referindo-se ao Index] em uma seção intitulada "Construindo currículos para todos" [...]. Isso liga a aprendizagem à experiência, local $\mathrm{e}$ globalmente, bem como a direitos e sustentabilidade ambiental. A aprendizagem é orquestrada de forma que as atividades de ensinar e aprender correspondem à diversidade de jovens dentro da escola. As crianças são encorajadas a ser ativas, reflexivas, aprendizes críticas e são vistas como um recurso mútuo às aprendizagens umas das outras. Os adultos trabalham juntos de forma a assumirem responsabilidade pela aprendizagem das crianças (BOOTH; AINSCOW, 2016, p. 50).

$\mathrm{Na}$ perspectiva Omnilética, as práticas não se referem predominantemente a nenhum aspecto específico, mas a todos os saberes-fazeres em movimento no cotidiano das instituições, incorporando, assim, as práticas de aprendizagem e curriculares, mas extrapolando-as para também contemplar práticas de gestão, de socialização, de planejamento, de organização, festivas etc.

Quanto à complexidade, Morin a defende como um pensamento em si mesmo, denominando-o de pensamento complexo (MORIN, 2015). Esse pensamento possui uma série de premissas epistemológicas, como sistemas abertos, princípio hologramático, ordem-desordem, auto-organização, relação sujeito-objeto e assim sucessivamente. No pensamento Omnilético, concordamos com a grande maioria delas e apropriamo-nos especificamente de duas: a ideia de recursividade e de incerteza.

O pensamento complexo empresta à perspectiva Omnilética a ideia de que, sendo, nós mesmos, sujeitos culturais, políticos e práticos, tecemos, infindavelmente, relações culturais, políticas e práticas que tanto se complementam quanto se contradizem; que tanto se negam quanto se reafirmam, e que esse próprio movimento nos causa uma percepção sempre temporária da(s) realidade(s), o que aponta para aberturas constantes a se perceber outras culturas, políticas e práticas em jogo, e consequentes (e incessantes) possibilidades de se observar/perceber/ser/fazer aquilo que ainda não esteja imediatamente visível, mas presente como potência, graças à nossa incerteza ontológica.

Por fim, com relação à dialética, apoiamo-nos no conceito de totalidade proposto por Lukács (2003), que a define, a partir de um ponto de vista de método, como o problema central, a condição primordial para o conhecimento da realidade. Vale lembrar que, para o autor, a realidade é a sociedade. Diz-nos Lukács (1979, p. 240): 
A categoria de totalidade significa [...], de um lado, que a realidade objetiva é um todo coerente em que cada elemento está, de uma maneira ou de outra, em relação com cada elemento e, de outro lado, que essas relações formam, na própria realidade objetiva, correlações concretas, conjuntos, unidades, ligados entre si de maneiras completamente diversas, mas sempre determinadas.

Isso posto, podemos afirmar que a perspectiva Omnilética é aquela que observa o jogo dialético e complexo entre culturas, políticas e práticas. Dito de outra maneira, inclusão, vista em uma perspectiva Omnilética, assume como ponto de partida a relação dialética e complexa entre três dimensões em que se manifesta a vida: culturais, políticas e práticas. Nesste sentido, a cada nova mirada na realidade, reconhecemos a complexidade (que é lógica, ética, auto-organizadora e exponencial em possibilidades) e a dialeticidade (totalizante, dinâmica, tensional e desveladora) presentes nas relações existentes entre valores e crenças (culturas), políticas (intenções e decisões que objetivam orientar ações) e práticas sociais (as ações propriamente ditas).

Nessa direção, na compreensão omnilética de inclusão em educação, ressaltamos seu caráter dinâmico, incerto e necessário por representar um movimento político mundial pautado na ideia de direitos humanos e de justiça social. Como tal, inclusão precisa constituir-se em processo infindável de busca pela minimização do sofrimento causado pela desigualdade promovida pelas contradições sociais, históricas e econômicas de nosso mundo atual.

Em linha semelhante, nossa compreensão omnilética de interculturalidade assume como ponto de partida a ideia de que as diferenças são condições basilares que nos permitem avançar em concepções e práticas de educação, de docência e de formação, que favoreçam o entendimento dessas concepções em variados contextos históricos e nacionais, culturais, políticos e práticos, dialética e complexamente intrincados, repensando e desconstruindo os padrões classificatórios e normatizantes presentes no universo educacional.

Quanto à inovação pedagógica, compreendemo-la como aquela prática que rompe com o paradigma da racionalidade técnica, baseada, entre outros aspectos, em lógica disciplinar e na pura transmissão de conhecimentos científicos. As práticas formativas inovadoras requerem entender aspectos culturais, políticos e práticos em jogo dialético e complexo para se promover a inovação curricular nos ambientes educacionais, um currículo que reconheça as diferenças, o desenvolvimento de posturas investigativas e o 
fortalecimento dos saberes mediante a participação ativa dos estudantes, entre outros aspectos.

\section{Resgatando a história da pesquisa: suas origens sua(s), metodologia(s) e sua atualidade}

A pesquisa Formação de educadores: inclusão, interculturalidade e inovação pedagógica em contextos internacionais de ensino superior originou-se a partir do desejo de construir uma rede de pesquisa no âmbito nacional e internacional que envolvesse pesquisadores e instituições interessados nas temáticas centrais. O primeiro encontro para discussão da proposta ocorreu durante o evento Universidade e Participação - UP3, promovido pelo LaPEADE /UFRJ, em 2013. O OIIIIPe consolidou-se como Observatório na quarta edição do mesmo evento, ou seja, Universidade e Participação - UP4, ocorrido em 2016.

Nossa metodologia de pesquisa estruturou-se tendo em vista atender aos diversos objetivos específicos que cada Instituição de Ensino Superior (IES) se destinou alcançar, de maneira a convergir no nosso objetivo geral, comum a todas as IES participantes da pesquisa em questão. Nesse sentido, nossas metodologias de pesquisa pretendem problematizar concepções culturais colonialistas que podem ser subestimadas no cotidiano da vida acadêmica, buscando possibilitar que as IES participantes identifiquem, reflitam criticamente e adotem mudanças institucionais que fortaleçam relações orientadas pela inclusão, pela inovação pedagógica e pela interculturalidade.

O percurso metodológico adotado nesta pesquisa envolve, portanto, a etnografia digital, pesquisa bibliográfica, pesquisa documental, pesquisa colaborativa e pesquisa-ação crítico-colaborativa.

No que diz respeito às pesquisas etnográficas da atualidade, elas sempre focam em determinado aspecto ou em alguma dimensão relacionada à cultura, pois elas tendem a abordar questões ou problemas específicos em um contexto específico ou comunidade que servem para estreitar e concentrar os esforços de investigação. Quando falamos em etnografia "digital", compreendemos que as diversas maneiras e instrumentos de que fazemos uso para a coleta de dados, sejam eles face a face ou por meios virtuais, são culturalmente construídos, ou seja, de alguma maneira o mundo real e o mundo virtual se entrelaçam formando o campo de estudo. Logo, a etnografia digital utiliza os seguintes instrumentos de coleta de dados: entrevistas, observação participante, chats, fóruns, salas 
virtuais e plataformas de aprendizagem. Hine (2000) esclarece-nos, portanto, que a diferença em grande medida entre as pesquisas focadas em ambientes digitais que se utilizam da etnografia [...] são as terminologias propostas para dar conta dessa "adaptação" do método etnográfico para o mundo virtual e suas implicações.

Quanto à pesquisa bibliográfica, Ludwig (2015) diz-nos que é o ato de procurar, recolher, analisar, interpretar e julgar as contribuições teóricas já existentes sobre certo assunto. Compreendemos que se trata de um passo significante e fundamental para qualquer pesquisa, pois nos dá a dimensão do que vem sendo produzido em determinado contexto, dando-nos a possibilidade de conhecer os caminhos pouco percorridos/estudados, o que nos oportuniza valorizar nosso foco de investigação.

No contexto de nosso estudo, a pesquisa bibliográfica faz-se fundamental, especialmente no que diz respeito ao estado atual das discussões sobre os conceitos e categorias centrais da pesquisa proposta: perspectiva omnilética, inovação pedagógica, interculturalidade, formação de educadores, processos identitários-culturais/processos de subjetivação indígena, inclusão no ensino superior, educação escolar (ou diferenciada) indígena, protagonismo político.

A pesquisa documental é outro percurso adotado em nossa pesquisa, pois, como afirma Cellard (2008), o uso de documentos em pesquisa permite, ainda, acrescentar a dimensão do tempo à compreensão do social. Sendo assim, consideramos que a utilização de documentos possibilita-nos desvendar uma riqueza de informações para que entendamos determinado contexto histórico e sociocultural, uma vez que nossa pesquisa envolve inúmeras IES, em diferentes Estados brasileiros e em diversos cenários internacionais.

Em nosso estudo, usamos como fontes documentais: orientações e diretrizes curriculares, leis e os materiais produzidos e disponibilizados na plataforma moodle, pelos investigadores participantes da pesquisa, sobre nossas temáticas-chave: interculturalidade, inovação e inclusão.

Ao considerarmos a pesquisa colaborativa, compreendemos que nosso estudo se trata de uma investigação que, apesar de possuir os objetivos específicos para cada IES participante, eles convergem no seu objetivo geral, o que, portanto, requer planejamento, execução de ações e obtenção de resultados plenamente compartilhados com todos os sujeitos envolvidos. 
Ainda no que tange às metodologias utilizadas em nossa pesquisa, direcionamos nosso olhar para a pesquisa-ação crítico-colaborativa por considerarmos e desejarmos desenvolver uma pesquisa com ação e ação com pesquisa, enfim, ação na pesquisa. Essa metodologia de pesquisa considera a "voz do sujeito, sua perspectiva, seu sentido, mas não apenas para registro e posterior interpretação do pesquisador, a voz do sujeito fará parte da tessitura da metodologia da investigação" (FRANCO, 2005, p. 486).

Por fim, diante do cenário metodológico adotado em nossa pesquisa e apresentado nesta seção, destacamos que já efetuamos a análise documental das instituições envolvidas, consolidamos o OIIIIPe, construímos o regimento interno, realizamos e continuamos a realizar encontros virtuais mensalmente e encontros presenciais em quatro diferentes Estados brasileiros, com o quinto e sexto encontros já planejados para o corrente ano.

Atualmente, encontramo-nos em fase de coleta de dados, a qual teve início com a aplicação de questionários, destinados ao público gestor das instituições de ensino superior participantes da pesquisa, o que num futuro breve será aplicado, depois dos devidos ajustes, para docentes e discentes das referidas instituições. Nosso objetivo, portanto, é levantar as concepções concernentes aos conceitos de inclusão, interculturalidade e inovação pedagógica, mapear propostas de ação e experiências sobre esses conceitos com relação à formação de educadores e identificar dispositivos colonizadores nas relações que permeiam o cotidiano das referidas universidades.

\section{Inclusão, interculturalidade e inovação pedagógica: contrapontos omniléticos nas vozes de gestores}

No intuito de apresentarmos um rastreamento histórico acerca da parceria do LaPEADE com o OIIIIPe no que diz respeito à pesquisa intitulada Formação de Educadores: inclusão, interculturalidade e inovação pedagógica em contextos internacionais de ensino superior, consideramos importante compartilharmos algumas compreensões das temáticas inclusão, interculturalidade e inovação pedagógica e a tradução delas nas ações realizadas na Universidade Federal do Rio de Janeiro (UFRJ).

Como mencionamos no final da seção anterior, nossa pesquisa efetuada pelo LaPEADE e OIIIIPe encontra-se em fase de coleta de dados. Inicialmente, aplicamos o 
questionário fazendo uso do Google Forms, ${ }^{5}$ o qual foi enviado para o público gestor de todas as universidades participantes da pesquisa. Tratando especificamente do universo de envios para os gestores da UFRJ, tivemos uma baixa devolutiva. Diante desse cenário, nossa equipe decidiu realizar entrevistas com alguns gestores de nossa instituição (UFRJ).

Analisaremos, de forma exploratória, a compreensão de dois gestores da UFRJ acerca das temáticas inclusão, interculturalidade e inovação pedagógica. Destacamos que os dois gestores entrevistados, um pró-reitor de pessoal e outra decana do Centro de Filosofia e Ciências Humanas $(\mathrm{CFCH})$, serão nomeados aqui como "R" e "D", respectivamente.

Ao questionarmos sobre a compreensão deles sobre inclusão, a entrevistada " $D$ " diz:

[...] a inclusão diz respeito a todas e qualquer uma das unidades acadêmicas do CFCH, o nosso centro universitário, além dessas unidades que eu já citei, tem a escola de serviço social, o núcleo de estudo de políticas públicas em direitos humanos, o instituto de psicologia, a escola de comunicação, são unidades que trabalham com o tema da inclusão. [...] A inclusão envolve necessariamente recepcionar e criar as condições para uma formação no nível profissional que é o nível da graduação, né, mas não só, de pesquisadores também, de propostas de intervenção de devolução para sociedade dessa produção do conhecimento, né, pra todos e quaisquer seres humanos, sejam eles com identidades diversas, de sexo, de gênero, de raça, de cor, de nacionalidade, de idade, de religião, incluir é tentar entender a dimensão humana do ser social porque a gente tá trabalhando com essa categoria do ser social de modo abstrato sem enraizá-la no conjunto das nossas relações cotidianas que são relações que se manifestam de modo interpessoal, mas que foi feito das relações sociais.

Consideramos que D apresenta um conceito amplo de inclusão em educação ao mencionar diferentes grupos e ações interdepartamentais distintas. A ideia de inclusão como forma de acolhimento e relações interpessoais demonstra o envolvimento e a atenção da entrevistada com o tema. Podemos interpretar que a respondente assume uma perspectiva omnilética de inclusão à medida que relaciona culturas (recepção, formação), políticas (políticas públicas, direitos humanos) e práticas (relações sociais e cotidiana) em

${ }^{5}$ O Google Forms é um serviço do Google cujo objetivo é facilitar a criação de formulários e questionários diversos. Disponível gratuitamente para todos que possuírem uma conta Google, o serviço pode ser acessado em diversas plataformas, como web, desktop e celular. Ele é útil para todos aqueles que queiram fazer um formulário de pesquisa ou de coleta de opiniões (Disponível em: <http://www.techtudo.com.br/tudosobre/google-forms.html>. Acesso em: 24 jan. 2018. 
uma dimensão complexa e dialética em que os processos se articulam de forma não fragmentada.

O respondente " $R$ " considera que:

Inclusão em Educação é um conceito que a gente devia considerar por ponto de vista da sociedade, como um todo, né?! As sociedades deveriam incorporar e serão sociedades para qualquer cidadão, independente da situação. [...] É a gente possibilitar a educação pra todos os indivíduos. Independente da sua condição, da sua situação.

Sua resposta também destaca a dimensão de educação como direito para todos, com destaque para a afirmação do papel da sociedade, ou seja, inclusão em educação é um aspecto da inclusão social. Essa compreensão favorece a visão totalizante, à qual temos dedicados nossos estudos, que têm compreendido a inclusão como processo infindável, dialético e complexo.

No que tange à compreensão dos referidos gestores sobre interculturalidade e inovação pedagógica, a entrevistada " $D$ ” entende que:

Essas temáticas, seja da interculturalidade, seja da inovação tecnológica, elas estão atravessadas por uma compreensão restrita do campo tecnológico ou do desenvolvimento das tecnologias educacionais; é preciso redimensionar e deslocar com esse sentido é bastante limitado para o tema em que a produção do conhecimento sobretudo o conhecimento na área das ciências humanas $e$ sociais deva ter necessariamente implicações práticas todo conhecimento produzido, seja do ponto de vista dos inventários, das diagnoses, dos balanços, das avaliações, seja do ponto de vista da construção de metodologias, pedagógicas, de intervenção no social através dos projetos da saúde pública, por exemplo, elas têm que ter todo um encadeamento com os projetos teóricos políticos que visem a sociedade, que visem um projeto de nação para onde a gente quer que o Brasil caminhe, qual é o projeto de sociedade que nos movimenta na formulação dessa perspectiva da interculturalidade e da inovação pedagógica (grifos nossos).

Superar a ideia que vincula inovação pedagógica à questão tecnológica tem sido um importante debate enfrentado pelos pesquisadores participantes da pesquisa. A associação entre interculturalidade e inovação pedagógica feita pela entrevistada D é particularmente relevante, à medida que julgamos necessário que haja ruptura de natureza cultural com as práticas "educativas" tradicionais que implicam processos de exclusão. Relacionar interculturalidade e inovação pedagógica pode ser uma forma de inspiração e abertura para a emergência de culturas novas, provavelmente estranhas aos olhares conformados com a tradição. A perspectiva da produção de conhecimento e projetos 
políticos que questionem o projeto de sociedade vigente, sobretudo que nos possibilite a superação do processo de descolonização das culturas, políticas e práticas, tem sido uma busca contínua em nossos estudos. Compreendendo a importância da gestão no processo de (des)construção dos espaços e tempos educativos, consideramos que a perspectiva discursiva adotada pela entrevistada $\mathrm{D}$ dialoga com nossos anseios, o que pode viabilizar avanços e a adoção de novos objetivos de pesquisa que envolvem a instituição em questão.

Nós queremos formar professores para quê? Para serem repetidores de tecnologias de inovação ou para despertarem as potencialidades dos nossos alunos para formação desse projeto de nação para constituição desse projeto de nação, então é trabalhar numa perspectiva libertadora e a atividade pedagógica deveria ser necessariamente nessa perspectiva, trabalhar com essa perspectiva implica romper com uma postura bastante conservadora, limitada, reduzida do processo do ensino e aprendizagem, como o processo bancário escolar que não permita às pessoas desenvolver suas capacidades, suas potencialidades.

Questionar a proposta de formação docente e articular esse processo ao conceito de inovação, inclusão e interculturalidade reitera o quanto a entrevistada D está envolvida com a perspectiva adotada em nossa pesquisa. A questão do isolamento e a falta de diálogo interinstitucional em muitos casos inviabilizam a consolidação de forças e projetos comuns. Pesquisas que envolvem diferentes instituições e buscam ouvir vozes diversas têm potencial para promover mudanças e repensar nossas práticas formativas. Por sua vez, o respondente $\mathrm{R}$ ressalta a importância do aspecto universal da educação e da cultura.

A cultura é transversal, ou deveria ser transversal, universal também [...] Pra você discutir interculturalidade não significa que você tá com ela segmentada, tudo bem que é parte da realidade, mas se você sucumbir a esse tipo de categorização, você um pouco... É meio contrassenso, é meio contraditório. Então preferiria ficar com educação e cultura tem que ser universal. [...] Inovar pedagogicamente, se discutir formas... Se isso tá vinculado a você mudar a forma como a gente ensina ou é ensinado, ou buscar formas pra que a gente possa chegar em quem tá demandando, chegar no estudante, da forma que ele entende, seja do ponto de vista da linguagem, seja do ponto de vista de você usar um vídeo, as redes sociais... Se trata desta forma, você pode entendê-la como um aspecto positivo, digamos assim, dentro do conceito de caminharmos caminhar rumo a educação universal.

Paradoxalmente, o discurso de R ressalta a importância de uma educação universal, entretanto menciona a relevância de dialogar e buscar formas específicas de atender à demanda dos estudantes. A tensão entre o universal e o relativo é retratada no discurso de $\mathrm{R}$ e está presente nas culturas, políticas e práticas docentes e institucionais. Tal tensão 
existe também em nossas pesquisas e em nossa constante busca pela coerência discurso/prática, daí a importância de desenvolver um olhar omnilético, que implica o questionamento de nossas próprias concepções e práticas, enquanto atores com múltiplas funções e identidades dialeticamente complexas, incertas e passíveis de serem transformadas e de mediar transformações.

\section{Considerações finais: desafios e possibilidades da pesquisa}

Nossas ações e pretensões têm sido pautadas na consolidação do OIIIIPe, o que implica a produção de subsídios para a construção de políticas públicas de ensino superior e o fortalecimento de redes de pesquisa e parcerias interinstitucionais nacionais e internacionais.

Assim, coletivamente, temos investido em ações de educação e difusão do conhecimento, de modo a desenvolver pesquisa, ensino e extensão em rede colaborativa, em níveis de graduação e de pós-graduação, com o propósito de formar profissionais da Educação que produzam saberes e práticas educativas críticas, transformadoras e orientadas por princípios de inclusão, interculturalidade, e inovação pedagógica.

Nossas pretensões e desafios envolvem ainda realizar o acompanhamento de políticas internas de inclusão nas instituições participantes; promover debates, fundamentados em princípios de inclusão, interculturalidade e inovação pedagógica, entre as IES participantes do OIIIIPe, acerca de decisões político-acadêmicas, segundo o referencial de cada uma dessas Instituições; sistematizar a produção de conhecimento científico sobre questões relevantes ao OIIIIPe; fazer circular nacional e internacionalmente as discussões de todos os encontros, regionais, nacionais e internacionais.

Para tanto, é necessário superarmos as barreiras institucionais, como as nossas próprias, que envolvem principalmente a participação e o comprometimento dos pesquisadores participantes, que tem sido um obstáculo contínuo na medida em que não temos atingido a participação de todos nas reuniões virtuais e presenciais, o que, consequentemente, tem impedido o cumprimento de tarefas nos prazos acordados.

A despeito dos desafios mencionados, somos impulsionados a continuar nossa pesquisa pelos ideais coletivos e pelo espírito colaborativo da proposta que tem alimentado nossas esperanças de lutar pela universidade pública, pelos nossos processos formativos 
oportunizados, pela relação e troca de experiências com pesquisadores de diferentes contextos e por acreditar, parafraseando Paulo Freire, que a educação é uma forma de intervenção no mundo.

\section{REFERÊNCIAS}

BOOTH, T.; AINSCOW, M. Index para a inclusão. Desenvolvendo a aprendizagem e a participação na escola. Tradução de M. P. Santos. UFRJ: Lapeade, 2011.

BOOTH, T.; AINSCOW, M. Index for inclusion: a guide to school development led by inclusive values. Cambridge: Index for Inclusion Network, 2016.

CAPELLINI, V. L. M. F. A avaliação das possibilidades do trabalho colaborativo no processo de inclusão escolar do aluno com deficiência mental. 2004. 299 f. Tese (Doutorado em Educação Especial) - UFSCar, São Carlos.

CELLARD, A. A análise documental. In: POUPART, J. et al. A pesquisa qualitativa: enfoques epistemológicos e metodológicos. Petrópolis: Vozes, 2008.

FRANCO, M. A. S. Pedagogia da pesquisa-ação. Educação e Pesquisa, São Paulo, v. 31, n. 3, p. 483-502, dez. 2005.

HINE, C. Virtual ethnography. London: Sage Publications, 2000.

LUDWIG, A. C. W. Fundamentos e prática de metodologia científica. 3. ed. Rio de Janeiro: Vozes, 2015.

LUKÁCS, G. Existencialismo ou marxismo. São Paulo: Livraria Editora Ciências Humanas, 1979.

LUKÁCS, G. História e consciência de classe: estudos sobre a dialética marxista. São Paulo: Martins Fontes, 2003.

LUKÁCS, G. Prolegômenos para uma ontologia do ser social. São Paulo: Boitempo, 2010.

MORIN, E. O método 1: a natureza da natureza. Porto Alegre: Sulina, 2005.

MORIN, E. Introdução ao pensamento complexo. Tradução de Eliane Lisboa. 5. ed. Porto Alegre: Sulina, 2015.

POLIVANOV, B. Etnografia virtual, netnografia ou apenas etnografia? Implicações dos conceitos. Disponível em:

<https://portalrevistas.ucb.br/index.php/esf/article/view/4621/3243>. Acesso em: 18 jun. 2013.

SANTOS, M. P. dos. Dialogando sobre inclusão em educação: contando casos (e descasos). Curitiba: CRV, 2013. 
SANTOS, M. P. dos.; SANTIAGO, M. C. Escola de Àbá: política curricular para a igualdade racial no município de Juiz de Fora/MG In: IX ENCONTRO DE PESQUISA EM EDUCAÇÃO DA REGIÃO SUDESTE. Pesquisa em Educação no Brasil: balanço do século XX e desafios para o século XXI. São Carlos: UFSCAR, 2009a.

SANTOS, M. P. dos.; SANTIAGO, M. C. As múltiplas dimensões do currículo no processo de inclusão e exclusão em educação. In: COLÓQUIO INTERNACIONAL DE POLÍTICAS E PRÁTICAS CURRICULARES: DIFERENÇAS NAS POLÍTICAS DE CURRÍCULO. Anais... João Pessoa, PB, 2009b.

SANTOS, M. P. dos.; SANTIAGO, M. C. Ciclo de formação de professores sobre inclusão em educação: em direção a uma perspectiva omnilética. In: REUNIÃO NACIONAL DA ANPED, 36., 2013, Goiânia. Anais... Rio de Janeiro: Anped, 2013. Disponível em: $<$ http://36reuniao.anped.org.br/pdfs_trabalhos_aprovados/gt15_trabalhos_pdfs/gt15_2901_ texto.pdf>. Acesso em: 20 jan. 2018.

\section{Como referenciar este artigo}

SANTOS, Mônica Pereira dos.; SANTIAGO, Mylene Cristina.; NASCIMENTO, Leyse Monick França. Histórico de formação e consolidação da pesquisa colaborativa em rede: OIIIIPe e lapeade em foco. Revista Ibero-Americana de Estudos em Educação, Araraquara, v. 13. n. esp. 2, p. 1236-1251, set., 2018. ISSN: 1982-5587. DOI: 10.21723/riaee.v13.nesp2.set2018.11639

Submetido em: 15/03/2018

Aprovado em: 19/06/2018 